\title{
Does a tailored intervention to promote adherence in patients with chronic lung disease affect exacerbations? A randomized controlled trial
}

Claudia Gregoriano ${ }^{1,2^{*}}$ (D), Thomas Dieterle ${ }^{1,3}$, Anna-Lisa Breitenstein ${ }^{1}$, Selina Dürr ${ }^{1}$, Amanda Baum, Stéphanie Giezendanner ${ }^{4}$, Sabrina Maier ${ }^{1}$, Anne Leuppi-Taegtmeyer ${ }^{3,5}$, Isabelle Arnet ${ }^{2}$, Kurt E. Hersberger ${ }^{2}$ and Jörg D. Leuppi ${ }^{1,3}$

\begin{abstract}
Background: Poor medication-adherence is common in chronic lung patients, resulting in reduced health-outcomes and increased healthcare-costs. This study aimed to investigate the impact of an acoustic reminder and support calls on adherence to inhaled therapy in asthma and COPD patients and to determine their effect on exacerbations.

Methods: This single-blinded randomized controlled trial investigated asthma and COPD patients during 6 months in an ambulatory setting. The intervention consisted of daily alarm clock and support phone calls, whenever use of rescue medication doubled or inhaled medication was not taken as prescribed. Primary outcome was time to next exacerbation. Frequency of exacerbations, adherence to inhaled medication and quality of life scores were secondary outcomes. Cox and Poisson regression were used to determine intervention effect on time to exacerbation and frequency of exacerbations, respectively.

Results: Seventy-five participants were assigned to the intervention group and 74 to usual follow-up care. During a median follow-up of 6.2 months, 22 and $28 \%$ in the intervention and control groups respectively, experienced at least

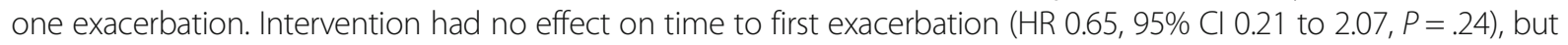
showed a trend toward a $39 \%$ decreased frequency of exacerbations ( $R R=0.61,95 \% \mathrm{Cl} 0.35$ to $1.03, P=.070$ ) for the adjusted models, respectively. The intervention group had significantly more days with $80-100 \%$ taking adherence regarding puff inhalers $(82 \pm 14 \%$ vs. $60 \pm 30 \%, P<.001)$ and dry powder capsules $(90 \pm .10 \%$ vs. $80 \pm 21 \%, P=.01)$. Timing adherence in participants using puff inhalers was higher in the intervention group ( $69 \pm 25 \%$ vs. $51 \pm 33 \%$, $P<.001)$. No significant differences in QoL were found between the two groups.
\end{abstract}

Conclusion: Participants assigned to the intervention group had significantly better taking and timing adherence of inhaled medication resulting in a trend towards a decreased frequency of exacerbations. However, no effect on time to next exacerbation was observed.

Trial registration: ClinicalTrials.gov: NCT02386722, Registered 14 February 2014.

Keywords: Chronic disease management, Compliance, Randomised controlled trial, Reminders

\footnotetext{
* Correspondence: c.gregoriano@gmail.com

'University Clinic of Medicine, Cantonal Hospital Baselland, Rheinstrasse 26,

$\mathrm{CH}-4410$ Liestal, Switzerland

${ }^{2}$ Department of Pharmaceutical Sciences, University of Basel, Basel,

Switzerland

Full list of author information is available at the end of the article
}

(C) The Author(s). 2019 Open Access This article is distributed under the terms of the Creative Commons Attribution 4.0 International License (http://creativecommons.org/licenses/by/4.0/), which permits unrestricted use, distribution, and reproduction in any medium, provided you give appropriate credit to the original author(s) and the source, provide a link to the Creative Commons license, and indicate if changes were made. The Creative Commons Public Domain Dedication waiver (http://creativecommons.org/publicdomain/zero/1.0/) applies to the data made available in this article, unless otherwise stated. 


\section{Background}

Asthma and chronic obstructive pulmonary disease (COPD) represent a major economic burden [1]. Poor adherence to prescribed medication is common in patients with asthma and COPD, varying from $<23-70 \%$ [2-5] . According to the World Health Organisation (WHO), adherence is defined as "the extent to which a person's behaviour corresponds with the agreed recommendations from a healthcare provider" [6]. Suboptimal or non-adherence to inhaled therapies has been shown to be associated with increased rates of morbidity, healthcare expenditures, hospitalisations, and mortality [7, 8]. Moreover, quality of life (QoL) is reduced [9] and medical care is used more often due to deterioration of symptoms and recurrent exacerbations [10].

Approximately $50-75 \%$ of healthcare expenditures related to COPD are caused by exacerbations [11], which often require hospital stays, physician visits, and additional medication. Moreover, exacerbations adversely affect patients' quality of life, lung function, and mortality [12]. A recent Swiss study has shown that a comprehensive selfmanagement asthma education programme can improve asthma control and patients' outcomes [13, 14]. Besides, it is noteworthy that higher adherence rates have been associated with lower exacerbation rates in patients with asthma [15, 16] and COPD [17].

Thus, sufficient adherence to medication is a prerequisite for the achievement of therapeutic success in chronic diseases. Various interventions and strategies for improving adherence have been described. Interventions which aimed at improving adherence are most successful when the use of electronic devices and feedback on patients' adherence behaviour are combined [18]. However, an intervention should be tailored to the individual patient's needs [19].

Therefore, the aims of this study were to investigate the effect of a patient-tailored intervention on adherence to inhaled therapy in patients with asthma and COPD and to determine the resulting effect on time to next exacerbation as well as exacerbation rates in the investigated study population.

\section{Methods}

\section{Study design}

This single-blinded randomized controlled study was conducted in an ambulatory setting in Switzerland (ClinicalTrials.gov: NCT02386722). The study details and baseline characteristics of the participating patients have been published previously [20, 21]. In brief, 169 adult participants with an established asthma-diagnosis according to the Global Initiative for Asthma (GINA) guidelines [22] and/ or an established COPD diagnosis according to the Global Initiative for Chronic Obstructive Lung Disease (GOLD) guidelines (severity GOLD I-IV based on the international GOLD-Criteria [23] were included in the study. Patients were recruited from several hospitals in the Basel region and from private practicing pulmonologists. They were followed-up every 2 months for a total of 6 months. All participants had to have experienced at least one exacerbation within the previous year and had to be treated with daily inhaled medication (controller medication for daily maintenance treatment). Participants remained on the treatment plan initiated by their general practitioner (GP). Written informed consent was obtained from every participant. Depending on the prescribed medication, all participants were equipped with Smartinhaler devices for puff inhalers such as metered dose inhalers and multidose dry powder inhalers (Adherium Ltd., Auckback, New Zealand) and/or with Electronic Monitoring System (POEMS) consisting of a printed, selfadhesive polymer film affixed to a multidose punch card (Pharmis GmbH, Beinwil am See, Switzerland) that had been prefilled with dry powder capsules. Each inhalation device actuation of the Smartinhaler was saved with date and time and data were transferred daily to an online database via wireless internet connection. Every time the patient broke a loop for taking the capsules, date and time were recorded on a microchip, which was read out every 2 weeks when participants brought back the empty punch card. In order to detect false device application, all participants were asked to demonstrate their inhalation technique with all prescribed devices to the investigator by using placebo devices (to avoid overdosing) at every study visit. The study was carried out in accordance with the Declaration of Helsinki and Good Clinical Practice guidelines. The local ethics committee northwest/central Switzerland (registry number: EK-269/13) approved the study.

\section{Randomisation}

A randomization list with study group allocation was generated by using R (RStudio, Boston, US). Participants were randomly assigned in a block size of two to the intervention or the control group. This reduced the risk of a season effect between the two study groups. Furthermore, participants were not aware of which group they had been randomized to (single-blinded). Patients were neither informed that there were two study groups nor about being allocated to a study group with or without supervision and support.

\section{Study intervention}

The intervention consisted of an audio-reminder generated by an app (for Smartinhaler devices) or an alarm clock (for POEMS) that were directly transferred to the 
participants' smartphones. Participants were allowed to choose the inhalation times themselves, depending on their GP's treatment plan, their personal habits and daily routine. Since in most cases the inhalation times during the morning or the evening do not differ even with several inhalation devices, patients received only one reminder which was valid for all devices prescribed at that time. In cases where patients were used to inhaling their medication at several time points during the day, a reminder was set for each inhalation. The audio-reminder and alarm clock generated for the study by the smartphone had to be switched off by the participants, which confirmed that the signal had been received. Participants in the intervention group received support calls from the study pharmacist or study nurses when the use of rescue medication doubled or when the medication was not inhaled as prescribed for more than two consecutive days (only for puff inhalers). During the support calls, the patients were first made aware of the missing inhalation during the past days and then, depending on the answer and the resulting reason for the non-adherence, the problems were specifically addressed in a tailored fashion with the aim to ensure regularity of inhalation. The content of the support calls was not based on a preprepared template. However, in order to standardize the process of the calls, the answers to the individual nonadherence problems were discussed in advance between the pharmacist and the study nurse who carried out the support calls. The content and duration of the calls were documented after each intervention. All participants (puff inhalers and dry powder capsules) also received a feedback on their intake pattern at each clinical visit, in the form of a visualization graph (Additional file 1).

Participants assigned to the control group did neither receive any reminder nor additional assistance or feedback regarding their medication adherence behaviour. Adherence data of these participants were analysed at the end of the study period and were not examined by the investigators during the study.

\section{Outcome assessment}

Sociodemographic variables such as age, gender and civil status were obtained by a generic questionnaire at the baseline visit. Smoking status, pack years (py) and body mass index (BMI) were assessed together with diseaserelated aspects such as allergies, number of exacerbations and hospitalisation during the previous 12 months.

The primary outcome was "time to next asthma or COPD exacerbation". Exacerbation was defined as acuteonset worsening of the patient's condition beyond dayto-day variations requiring interaction with a healthcare provider [24]. Time to next exacerbation was defined as the number of days between study begin and the first exacerbation. For patients treated at the Cantonal Hospital
Baselland, internal medical records could be screened to collect the needed information regarding exacerbations. For patients treated elsewhere, the treating physician was contacted to collect the necessary information. The following secondary outcomes were recorded and analysed: Frequency of exacerbation (defined as the number of exacerbations during the study period), the number of severe exacerbations which led to a hospitalisation, timing- and taking-adherence and health-related quality of life (QoL).

Adherence was quantified by using Smartinhalers and POEMS devices [20], starting at the baseline visit and continuing until the end of the study. Smartinhalers were used for the inhalation with puff inhalers (metered dose inhalers, Turbohaler, Discus and Ellipta ${ }^{\circ}$. Once the devices were installed on the inhalers, participants were able to use their medication as usual. POEMS were used for inhalation with dry powder capsules. When any therapy adjustments with additional inhaled medication or with a new treatment plan from the treating physician occurred, patients were instructed to inform the study team immediately. The study team prepared the necessary adjustments and informed the patients about the next steps (for example new Smartinhaler-delivery medication change to be carried out by the patients themselves) in order to be able to guarantee a seamless measurement of the adherence.

Objective adherence was quantified based on the following pre-specified criteria [25]:

- Taking adherence $=$ [number of puffs inhaled during $24 \mathrm{~h} /$ number of puffs prescribed during $24 \mathrm{~h}$ ) $\times$ 100. Correct taking adherence was considered when taking adherence was between 80 and 100\% (target range), based on previous studies [26].

- Timing adherence $=$ [number of correct dosing intervals during $24 \mathrm{~h} /$ number of dosing intervals during $24 \mathrm{~h}) \times 100$; correct dosing intervals was defined as an interval within a grace period of $25 \%$, i.e. between

$18-30 \mathrm{~h}$ for once daily dosing,

9-15 $\mathrm{h}$ for twice daily dosing and

$6-10 \mathrm{~h}$ for three times daily dosing.

- Gaps $=$ [number of days without inhalation during the study period / number of days of the study period] $\times 100$.

- Maximal gap length $=$ longest period of time (in days) without inhalation.

For the adherence calculation only the regularly inhaled medication was considered. Rescue inhalers which were only inhaled when needed, were not included in the adherence calculations. 
For the case that patients had multiple devices, adherence was calculated for each single device and then the median was calculated for every single day. Adherence of puff inhalers and dry powder capsules were calculated and evaluated separately, due to the fact the adherence was assessed with different methods.

Health-related QoL was assessed using the St. George Respiratory Questionnaire (SGRQ) [27]. Permission for the use of the SGRQ has been obtained by the St George's University of London (St George's Hospital Medical School).

Missing values of tests or clinical examinations were not included in the corresponding results, but were no reason to exclude the patients from the study.

\section{Sample size calculation}

Power calculation was based on the primary outcome measure "time to next exacerbation." Details of the sample size calculation can be found in the published protocol [20]. Briefly, an $80 \%$ power to detect a hazard ratio (HR) of 0.36 for time to next exacerbation in the intervention group was expected by including 70 patients in each group.

\section{Statistical analysis}

Statistical analyses were performed using the software $\mathrm{R}$ 3.1.3 [28] and the SPSS software package (version 23, IBM, Germany). Statistical significance was set at the 5\% level. Data are presented as mean and standard deviation (SD) or number and percentage (\%). Differences between intervention and control group were assessed using t-test for continuous parametric variables, and the Mann-Whitney Utest for non-parametric variables. For categorical variables, the Pearson's chi-square test was used. Poisson regression was used to analyse the number of exacerbations within the study period (uncensored across the entire 6-months) with respect to the effect of being in the intervention group versus the control group. Time to next exacerbation was assessed using survival analyses. Median follow-up was calculated across censoring time (i.e. participants without exacerbation). Univariate analyses were performed based on the Cox proportional hazards model (censored at the first exacerbation), using group as the independent variable. Results are reported as HR with a corresponding confidence interval (CI) of $95 \%$ and $p$-value. Exacerbation-free survival curves for the two groups were estimated and visualized by the Kaplan-Meier product limit method and compared using the log rank test.

Considering that the intervention and control groups differed in some characteristics at baseline, the association of these variables with both the incident exacerbations and time to next exacerbation were assessed using univariate Poisson regression and Cox regression, respectively (Additional file 2). Variables with a significant association $(P<.05)$ in univariate analysis were then entered into the multivariate model as possible confounders of the association between allocated group and incident exacerbations or time to next exacerbation.

The robust nonparametric analysis of longitudinal adherence data was conducted with the nparLD r package (function f1.ld.f1) to determine the effects of the factors time (1-200 days) and group (control and intervention) on different measures of adherence in percent (taking, timing) [29]. Such nonparametric methods are also robust with respect to outliers, missing data and small sample sizes.

\section{Results}

Figure 1 provides an overview of the study flow. One hundred sixty-nine participants met the inclusion criteria and were willing to participate in the study. Four participants withdrew consent prior to randomization so that $165 \mathrm{pa}$ tients were assigned either to the intervention or to the control group. Further 16 participants withdrew during the follow-up due to different reasons, so that 149 participants completed the study and were investigated for the planned analysis. Three (2\%) subjects had more than $25 \%$ of missing outcome data due to technical problems. Due to this small proportion of subjects with missing outcome variables and its random distribution, it was decided that there was no need to impute missing data (as originally planned in the study protocol) and to exclude these subjects from the Poisson regressions and robust nonparametric analysis of longitudinal data. Instead, we conducted a complete case analysis. Cox regression was performed with all subjects $(n=149)$.

\section{Baseline characteristics}

Baseline patient characteristics together with the prescribed medication at baseline are summarized in Table 1. Participants in the intervention group were younger, smoked less, and more of them had asthma compared to participants in the control group. Furthermore, patients assigned to the intervention group had less LAMA prescriptions.

\section{Time to next exacerbation}

Median follow-up time was $6.2 \pm 0.52$ months. During the study period, $37(24.8 \%)$ participants experienced one or more exacerbations (endpoints); Sixteen (21.3\%) of these were in the intervention and $21(28.3 \%)$ were in the control group $(P=.30$, Chi square test). A longer average time to the next exacerbation was observed in the intervention compared to the control group (102 days [95\% CI, 76 to 128] vs. 86 days [95\% CI, 66 to 106], $P=.19$ ), but failed to reach a statistical significance.

Survival analysis indicated that the probability of no exacerbation was $78 \%$ [95\% CI: 69 to $88 \%$ ] for the intervention 


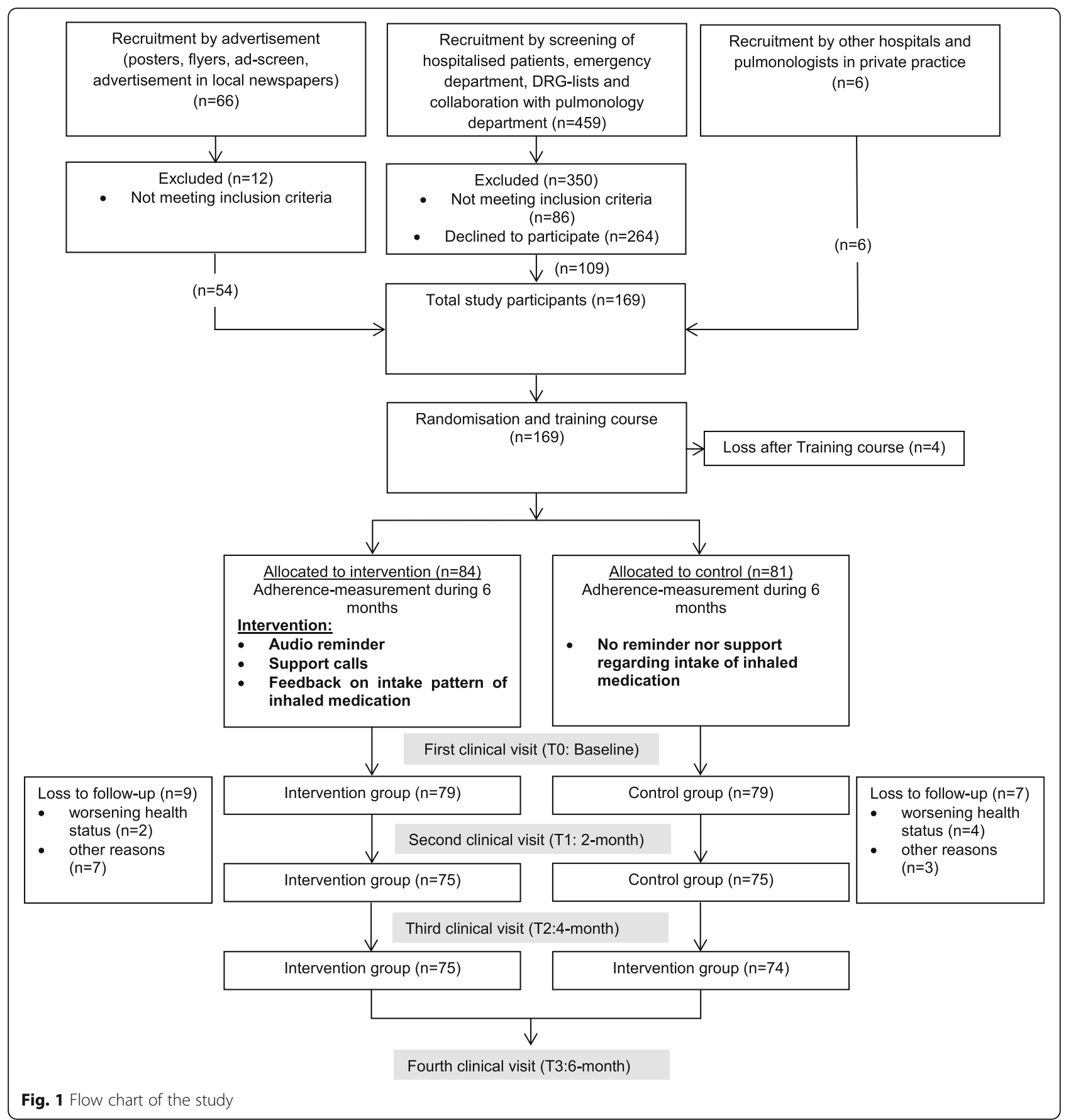

group and 71\% [95\% CI: 62 to 83\%] for the control group after 200 days (Fig. 2). Patients in the intervention group had a hazard ratio of 0.67 for the unadjusted model $(95 \% \mathrm{CI}$, 0.36 to 1.33 , one-sided, $P=.14$ ), meaning they were 0.67 times as likely as participants in the control group to experience at least one exacerbation during the study period. The multivariable analysis adjusted for age, lung disease and pack years showed a hazard ratio of 0.658 (95\% CI, 0.21 to 2.07 , one-sided, $P=.0 .237$ ) (see Additional file 2 for the selection of the confounders).

\section{Frequency of exacerbations}

In total, there were 60 exacerbations during the study period; including 12 severe exacerbations requiring hospitalisation (Table 2).

Poisson regression analysis indicated a significant effect of group for the unadjusted model. The coefficient for the intervention group was $-0.56(95 \% \mathrm{CI},-1.10$ to $-0.04, P=.037)$. This means that the expected log count for the intervention group decreased by -0.56 relative to the control group. In terms of relative ratios or rate 
Table 1 Baseline patient characteristics $(n=149)$. Values are numbers (percentages) unless stated otherwise

\begin{tabular}{|c|c|c|}
\hline Characteristics & Intervention $(n=75)$ & Control $(n=74)$ \\
\hline Mean (SD) age [years] & $64.7(12.4)$ & $69.0(8.8)$ \\
\hline Men & $46(61)$ & $51(69)$ \\
\hline \multicolumn{3}{|l|}{ Civil status } \\
\hline Unmarried & $7(9)$ & $10(14)$ \\
\hline Married & $46(61)$ & $48(65)$ \\
\hline Divorced/widowed & $22(29)$ & $16(22)$ \\
\hline \multicolumn{3}{|l|}{$\begin{array}{l}\text { Highest level of education at school } \\
\text { [n] }\end{array}$} \\
\hline Primary school & $10(13)$ & $11(15)$ \\
\hline Apprenticeship & $38(50)$ & $52(70)$ \\
\hline Higher professional education & $14(19)$ & $6(8)$ \\
\hline $\begin{array}{l}\text { University-entrance Diploma/ } \\
\text { Commercial college }\end{array}$ & $2(3)$ & $1(1)$ \\
\hline $\begin{array}{l}\text { University / Collage of higher } \\
\text { education }\end{array}$ & $11(15)$ & $4(6)$ \\
\hline \multicolumn{3}{|l|}{ Employment status [n] } \\
\hline Active worker & $23(31)$ & $15(20)$ \\
\hline Pensioner & $47(63)$ & $57(77)$ \\
\hline Never active worker & $5(6)$ & $2(3)$ \\
\hline \multicolumn{3}{|l|}{ Diagnosed lung disease } \\
\hline Asthma & $30(40)$ & $16(22)$ \\
\hline COPD & $32(43)$ & $45(61)$ \\
\hline Asthma-COPD- overlap & $13(17)$ & $13(17)$ \\
\hline \multicolumn{3}{|l|}{ Smoking status } \\
\hline Current smoker & $16(21.3)$ & $12(16.2)$ \\
\hline Non-smokers & $19(25.3)$ & $14(18.9)$ \\
\hline Ex-smokers & $40(53.3)$ & $48(64.9)$ \\
\hline Mean (SD) pack-years [n] & $28.6(32.8)$ & $41.2(34.3)$ \\
\hline History of allergy & $35(47)$ & $29(39)$ \\
\hline Mean (SD) body mass index $\left[\mathrm{kg} / \mathrm{m}^{2}\right]$ & $26.5(4.2)$ & $28.0(5.6)$ \\
\hline \multicolumn{3}{|l|}{ GOLD stage } \\
\hline $1\left(\mathrm{FEV}_{1}>80 \%\right.$ predicted), mild & $2(4)^{a}$ & $6(10)^{b}$ \\
\hline $2\left(\mathrm{FEV}_{1}, 50-80 \%\right.$ predicted), moderate & $20(45)^{a}$ & $24(42)^{b}$ \\
\hline 3 (FEV, $30-50 \%$ predicted), severe & $19(42)^{a}$ & $21(36)^{b}$ \\
\hline $4\left(\mathrm{FEV}_{1}<30 \%\right.$ predicted $)$, very severe & $4(9)^{\mathrm{a}}$ & $7(12)^{b}$ \\
\hline Mean (SD) FEV 1 predicted [\%] & $63.9(25.0)$ & $56.5(23.5)^{c}$ \\
\hline Mean (SD) FEV $1 / F V C$ predicted [\%] & $70.3(20.7)$ & $67.1(22.1)^{c}$ \\
\hline Mean SGRQ symptoms score (SD) & $45.7(21.5)$ & $48.7(25.6)$ \\
\hline Mean SGRQ activity score (SD) & $45.2(19.3)$ & $52.4(23.7)$ \\
\hline Mean SGRQ impact score (SD) & $21.8(14.6)$ & $29.3(20.7)$ \\
\hline Mean SGRQ total score (SD) & $32.5(14.7)$ & $39.6(20.3)$ \\
\hline Mean (SD) inhaled medication [n] & $1.9(0.8)$ & $2.0(0.8)$ \\
\hline Mean (SD) co-morbidities [n] & $1.8(1.6)$ & $2.2(1.7)$ \\
\hline \multicolumn{3}{|l|}{ Co-existing illnesses [n] } \\
\hline Diseases of the cardiovascular system & $44(59)$ & $46(62)$ \\
\hline
\end{tabular}


Table 1 Baseline patient characteristics $(n=149)$. Values are numbers (percentages) unless stated otherwise (Continued)

\begin{tabular}{|c|c|c|}
\hline Characteristics & Intervention $(n=75)$ & Control $(n=74)$ \\
\hline $\begin{array}{l}\text { Endocrine, nutritional and metabolic } \\
\text { diseases }\end{array}$ & $18(24)$ & $19(26)$ \\
\hline $\begin{array}{l}\text { Diseases of the gastrointestinal } \\
\text { system }\end{array}$ & $10(13)$ & $8(11)$ \\
\hline $\begin{array}{l}\text { Diseases of the musculoskeletal } \\
\text { system and connective tissue }\end{array}$ & $16(21)$ & $16(22)$ \\
\hline $\begin{array}{l}\text { Mean (SD) exacerbations } \\
\text { (last } 12 \text { months) [n] }\end{array}$ & $1.7(0.9)$ & $2.07(1.4)$ \\
\hline $\begin{array}{l}\text { Mean (SD) exacerbations with } \\
\text { hospitalisation (last } 12 \text { months) [n] }\end{array}$ & $0.4(0.6)$ & $0.7(1.0)$ \\
\hline \multicolumn{3}{|l|}{ Medication [n] } \\
\hline LABA/LAMA combinations & $10(13)$ & $9(12)$ \\
\hline LABA/ICS combinations & $52(69)$ & $53(72)$ \\
\hline LAMA & $26(35)$ & $41(55)$ \\
\hline LABA & $14(19)$ & $6(8)$ \\
\hline ICS & $10(13)$ & $5(7)$ \\
\hline SABA & $32(43)$ & $34(46)$ \\
\hline SABA/SAMA combinations & $2(2.7)$ & $2(2.7)$ \\
\hline \multicolumn{3}{|l|}{$\begin{array}{l}\text { Number of inhaled medication } \\
\text { at baseline }\end{array}$} \\
\hline 1 & $22(29.3)$ & $23(31.1)$ \\
\hline 2 & $36(48.0)$ & $27(36.5)$ \\
\hline 3 & $16(21.3)$ & $23(31.1)$ \\
\hline 4 & $1(1.3)$ & $1(1.4)$ \\
\hline
\end{tabular}

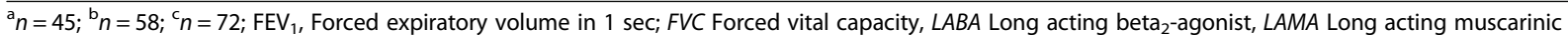
antagonist, ICS Inhaled corticosteroid, SABA Short acting beta ${ }_{2}$-agonist, SGRQ St. George Respiratory Questionnaire

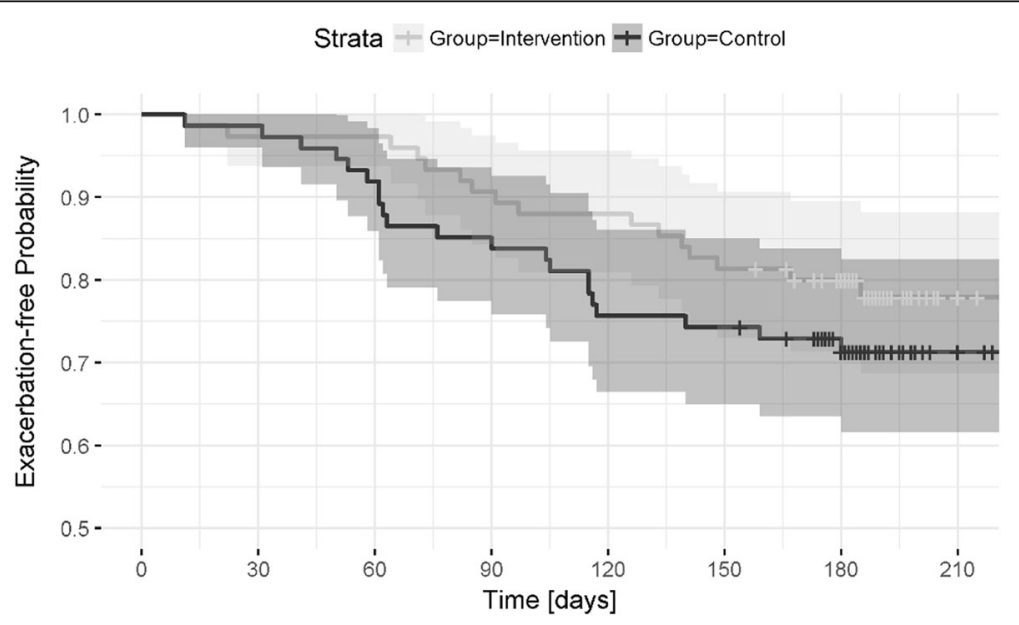

Number at risk

\begin{tabular}{|c|c|c|c|c|c|c|c|}
\hline$\frac{⿱ \mathbb{g}}{\sigma}=75$ & 73 & 73 & 68 & 66 & 61 & 52 & 5 \\
\hline ڤँ 74 & 73 & 68 & 63 & 56 & 55 & 44 & 6 \\
\hline 0 & 30 & 60 & 90 & 120 & 150 & 180 & 210 \\
\hline
\end{tabular}

Fig. 2 Kaplan-Meier analysis for the comparison of the time to next exacerbation in patients in the intervention compared to the control group 
Table 2 Frequency of total exacerbations $(n=60)$ and severe exacerbations $(n=12)$ in the intervention and control group during the study period

\begin{tabular}{|c|c|c|c|c|c|c|c|}
\hline \multirow[t]{2}{*}{ Exacerbations } & & \multicolumn{5}{|c|}{ Number of exacerbation per person } & \multirow{2}{*}{$\begin{array}{l}\text { Total number of } \\
\text { exacerbations, } n \text { [\%] }\end{array}$} \\
\hline & & 0 & 1 & 2 & 3 & 5 & \\
\hline Intervention ( $n=75)$ & Frequency & 59 & 11 & 4 & 1 & & $22(36.7)$ \\
\hline \multirow[t]{2}{*}{ Control $(n=74)$} & Frequency & 53 & 11 & 5 & 4 & 1 & $38(63.3)$ \\
\hline & & & & & & Total: & $60(100)$ \\
\hline \multirow[t]{2}{*}{ Severe Exacerbations } & & \multicolumn{5}{|c|}{ Number of exacerbation per person } & $\begin{array}{l}\text { Total number of } \\
\text { exacerbation, n [\%] }\end{array}$ \\
\hline & & 0 & 1 & 2 & 3 & & \\
\hline Intervention $(n=75)$ & Frequency & 70 & 4 & 1 & & & $6(50)$ \\
\hline \multirow[t]{2}{*}{ Control $(n=74)$} & Frequency & 70 & 3 & 0 & 1 & & $6(50)$ \\
\hline & & & & & & Total: & $12(100)$ \\
\hline
\end{tabular}

Total number of exacerbations in the intervention group: $(59 * 0)+\left(11^{*} 1\right)+(4 * 2)+(1 * 3)=22$; Total number of exacerbations in the control group: $\left(53^{*} 0\right)+\left(11^{*} 1\right)+\left(5^{*} 2\right)+\left(4^{*} 3\right)+(1 * 5)=38$; Total number of severe exacerbations in the control group: $\left(70^{*} 0\right)+\left(4^{*} 1\right)+(1 * 2)=6 ;$ Total number of severe exacerbations in the control group: $(70 * 0)+(3 * 1)+(0 * 2)+(1 * 3)=6$

ratios $(\mathrm{RR})$, the results indicated an incident rate for the intervention group which was 0.57 times the incident rate for the control group $(\mathrm{RR}=0.57,95 \% \mathrm{CI}, 0.33$ to 0.95). Respectively, in terms of percent change in the incident rate of exacerbations; the results indicated a $43 \%$ decrease for the intervention group compared with the control group. The multivariable analysis adjusted for lung diseaseshowed a relative ratio of 0.61 (95\% CI, 0.35 to $1.03, P=.070$ ), resulting in a $39 \%$ decreased rate on the number of exacerbations (see Additional file 2 for the selection of the confounders). There was no significant effect of group for severe exacerbations (Poisson regression, $P=.98$ ).

\section{Objective adherence}

Three participants had to be excluded from the adherence analysis due to more than $25 \%$ missing adherence data resulting from technical problems concerning the adherence measurement devices which failed to record the dose application. A mean of $7.17 \pm 9.72$ (range: 0-51) support calls per participant were performed throughout the study period in the intervention group with a mean duration of $3.0 \pm 1.00 \mathrm{~min}$.

\section{Taking and timing adherence}

Data on taking and timing adherence are provided in Table 3. Calculations for puff inhalers were based on $n=117$ subjects and for dry powder capsules on $n=90$ subjects. The number of monitored days was comparable for puff inhaler and dry powder capsule use in both groups.

The number of days in the pre-specified adherence target range (80-100\%) was significantly higher in participants assigned to the intervention compared to the control group. Timing adherence with puff inhalers was significantly higher in the intervention group (Table 3). Despite a strong trend towards greater timing adherence with dry powder capsules, the difference between the two study groups did not reach statistical significance.

Table 3 Mean percentage of days in target range for taking and timing adherence

\begin{tabular}{|c|c|c|c|}
\hline Variable & Intervention & Control & $P$ value \\
\hline \multicolumn{4}{|l|}{ Taking adherence } \\
\hline $\begin{array}{l}\text { Mean (SD) days in target range } \\
121 \text { for puff inhalers [\%] }\end{array}$ & $81.6(14.2)^{a}$ & $60.1(30.3)^{c}$ & $<.001$ \\
\hline $\begin{array}{l}\text { Mean (SD) days in target range } \\
121 \text { for dry powder [\%] capsules }\end{array}$ & $89.6(9.8)^{b}$ & $80.2(21.3)^{d}$ & .01 \\
\hline \multicolumn{4}{|l|}{ Timing adherence } \\
\hline $\begin{array}{l}\text { Mean (SD) days with correct } \\
\text { dosing interval for puff Inhalers [\%] }\end{array}$ & $68.9(25.0)^{\mathrm{a}}$ & $50.6(32.5)^{c}$ & $<.001$ \\
\hline $\begin{array}{l}\text { Mean (SD) days with correct dosing } \\
\text { interval for dry powder capsules [\%] }\end{array}$ & $79.6(12.9)^{b}$ & $71.7(22.0)^{d}$ & .052 \\
\hline
\end{tabular}


Table 4 Mean percentage of gaps and maximal gap length

\begin{tabular}{|c|c|c|c|}
\hline Variable & Intervention & Control & $P$ value \\
\hline Mean (SD) gaps for puff inhalers [\%] & $3.2(4.7)^{\mathrm{a}}$ & $11.7(18.6)^{c}$ & .008 \\
\hline $\begin{array}{l}\text { Mean (SD) gaps for inhalation with } \\
\text { dry powder capsules [\%] }\end{array}$ & $4.6(4.4)^{b}$ & $9.8(8.9)^{d}$ & .009 \\
\hline $\begin{array}{l}\text { Mean (SD) maximal gap length for } \\
\text { puff inhalers [days] }\end{array}$ & $1.6(2.0)^{\mathrm{a}}$ & $11.6(25.6)^{c}$ & .025 \\
\hline $\begin{array}{l}\text { Mean (SD) maximal gap length for } \\
\text { dry powder capsules [days] }\end{array}$ & $2.6(2.7)^{b}$ & $5.9(5.2)^{d}$ & .002 \\
\hline
\end{tabular}

\section{Gaps}

Significantly lower percentages of gaps for inhalation were observed in the intervention group with puff inhalers and dry powder capsules. Maximal gap length was significantly shorter for both, puff and dry powder capsules (Table 4). Sixteen participants assigned to the intervention with puff inhalers (16.4\%) and four with dry powder capsules $(4.1 \%)$ had no gaps during the whole study period. In the control group 14 participants with puff inhalers $(12.8 \%)$ and two participants with dry powder capsules $(1.8 \%)$ were identified without gaps.

\section{Nonparametric test for time and group effects on adherence}

The results of the nonparametric analysis of longitudinal data in factorial experiments are shown as online supplementary material (Additional file 3). Significant group effects were found for taking adherence with puff inhalers and dry powder capsules, and for timing adherence.

The group effect of the intervention group for taking and timing adherence is illustrated in Additional file 3. The larger effect in the intervention group is maintained throughout the whole study period and it is more clearly distinguishable for the taking adherence with puff inhalers (A) compared to the taking adherence with dry powder capsules (B). Similar results were observed for the timing adherence (C-D). A larger effect can be observed for the intervention group with a major difference for timing adherence with puff inhalers $(\mathrm{C})$.

\section{Health-related QoL}

Significant differences between the intervention and control groups were found at baseline regarding SGRQ total score and the subscale activity (Table 5). After 6 months, no significant differences in QoL were found between the two groups.

\section{Discussion}

In this randomized controlled trial of an intervention promoting adherence to inhaled therapy a significant improvement in taking and timing adherence of inhaled medication could be demonstrated. A trend towards a decreased frequency of exacerbations was observed among participants in the intervention group.

No effect on time to next exacerbation or on the hazard of experiencing at least one exacerbation during the follow-up period was observed between the two study groups.

\section{Exacerbations during study period}

The non-significant difference for the time to next exacerbation between the study groups could be explained by the follow-up period being too short or the participant number too low compared with other studies [30,31]. Clinical studies also tend to include

Table 5 Changes in SGRQ scores after 6 months

\begin{tabular}{|c|c|c|c|c|}
\hline Variable & Symptoms & Activity & Impact & Total Score \\
\hline \multicolumn{5}{|l|}{ Intervention } \\
\hline Baseline (Mean (SD)) & $45.7(21.5)$ & $45.2(19.3)$ & $21.8(14.6)$ & $32.5(14.7)$ \\
\hline 6-month change $(95 \% \mathrm{Cl})$ & $-0.59(4.3$ to -5.5$)$ & 0.2 (3.9 to -3.5$)$ & $1.3(4.7$ to -1.9$)$ & 0.7 (3.7 to -2.4$)$ \\
\hline \multicolumn{5}{|l|}{ Control } \\
\hline Baseline (Mean (SD)) & $48.7(25.6)$ & $52.4(23.7)$ & $29.3(20.7)$ & $39.6(20.3)$ \\
\hline 6-month change $(95 \% \mathrm{Cl})$ & $-2.9(2.8$ to -8.8$)$ & 0.1 (3.8 to -3.5$)$ & $-2.0(1.2$ to -5.2$)$ & $-1.5(1.5$ to -4.5$)$ \\
\hline \multicolumn{5}{|l|}{$P$ value } \\
\hline Baseline & .44 & .03 & .05 & .02 \\
\hline 6 months change & .53 & .70 & .29 & .77 \\
\hline
\end{tabular}

SD Standard, Cl Confidence interval 
highly motivated participants causing a selection bias that influences health-outcomes in this type of study [32]. The current finding that participants in the intervention group experienced a trend towards a decreased frequency of exacerbations is supported by the fact that adherence in this group was significantly higher compared to the control group. This could also be shown in other studies, where high adherence, as in our study, was found to be associated with reduced exacerbation rates in asthma $[10,15,16,33]$ and COPD patients [17]. Furthermore, it could also be shown that patients with infrequent inhaler use had an increased rate of healthcare use. This, indicates that there is a clear association between adherence behaviours and clinical outcomes [34].

\section{Objective adherence}

Adherence to inhaled medication has been investigated in a variety of clinical trials. However, the many of the studies conducted with asthma and COPD patients used prescription refill adherence or self-report measurements to assess the inhaled medication adherence [35]. The most frequently used adherence measure methods in the last 10 years were self-report measurements (38\%), prescription refill data (33\%) and electronic monitoring (19\%) [35].

In comparison to previous studies applying subjective adherence measurements [36] or medication refill adherence [37], this study adds objectively acquired adherence data, which provide a more accurate view of the patient's everyday adherence situation as well as of the effect of the applied intervention.

Adequate adherence to chronic therapies is of major importance for achieving therapeutic success. A Cochrane systematic review which analysed randomized controlled trials to improve adherence to pharmacological regimens showed that less than $50 \%$ of the interventions reached a significant improvement of adherence and only $30 \%$ demonstrated improved clinical outcomes [38]. For a successful intervention, the review suggested that frequent interaction with the patients focusing on adherence should be guaranteed. The results of this study confirm and further support this suggestion. Frequent interactions in form of patient-tailored, regular support calls whenever patients became non-compliant appear to represent a significant advantage compared to studies with limited and predefined follow-up appointments during the study period and can also explain the successful and significant improvement on the adherence achieved with this intervention. These findings are supported by a randomised clinical trial conducted by Sulaiman et al., which showed that repeated feedback as an intervention can significantly improve inhaler adherence [39].
Participants assigned to the intervention group had significantly better adherence. This shows that reminders can support patients to avoid forgetting to take their prescribed inhaled medication. These results are also confirmed by a systematic review which investigated the effect of electronic medication packaging devices on adherence indicating an increase of up to 34\% [40]. Several other randomized controlled trials using electronic monitoring devices and reminder functions to study adherence to inhaled medication have likewise shown a significant improvement in adherence of different inhaled medication classes $[41,42]$. Further, The improvement of medication adherence after a pharmacist intervention has already been confirmed in patients suffering from COPD [43] and asthma [44].

Furthermore, participants who inhaled with dry powder capsules had a higher percentage of days within the defined target range. This can be explained by the fact that medication available for dry powder capsules has a once-daily regimen and is thus easier to follow. This result is in line with other clinical trials which confirmed that taking and timing adherence were higher for oncedaily regimens compared to two times or three times daily regimens [45]. The higher adherence rate obtained with electronic punch cards containing dry powder capsules might be explained by their simultaneous function as a visual reminder [46].

Overall, taking and timing adherence were relatively high for puff inhalers and dry powder capsules, within both study groups. A positive selection bias might be present which can influence the adherence. This could explain why participating patients already had a relatively high level of adherence and why it is therefore challenging to identify a positive effect on patients' health-outcomes $[47,48]$.

\section{Health-related QoL}

The intervention showed no effect on QoL. The follow-up period may have been too short to detect a clinical significance. Moreover, the mean SGRQ total score for all participants was very low, generally indicating a good health status of the participants. Therefore, the possibility of reaching a clinically significant improvement is reduced. Similarly, other studies have observed comparable results when analysing health-related QoL after an intervention $[43,49]$. However, studies that detected a significant improvement in QoL included a larger number of participants and all of them had a relatively poor QoL at baseline $[50,51]$. The similar outcomes regarding QoL in both study groups can also be explained by a parallel effect of the study. Due to the fact that all participants received a general training course, experienced regular follow-up visits and had monitoring devices, it is likely that the control group also experienced a positive effect. Furthermore, 
wrong inhalation technique was corrected in all participants on ethical grounds, which is also likely to have influenced the results.

\section{Strengths and limitations}

To our knowledge, our study is the first to investigate a population affected by asthma and/or COPD, which are different diseases however, certain important aspects in common. The aim to improve adherence to inhaled medication in order to achieve better outcomes, constitutes a common approach for these two diseases. Moreover, in previous similar studies of adherence and outcome, only the adherence to a preselected medication class was investigated. The current study, however, imposed no restrictions regarding medication class. This reflects a real-life situation for the participants, since they do not experience any drug changes due to the study. Second, there was real-time monitoring for the puff inhalers, which allowed a direct intervention without any delays. We acknowledge some limitations. First, adherence monitoring was unblinded. All participants were aware of the fact that adherence was measured throughout the whole study using the electronic devices. This could have caused a "Hawthorne effect" [52], which can elicit a bias in the data. Second, attention should be paid to the fact that two different lung diseases (asthma and COPD) were observed and analysed bearing the potential for unequal responses to medication, which may have affected the frequency of exacerbations in the study population. Third, the two study groups differ significantly concerning some baseline parameters that could have influenced the study results. In order to account for this imbalance, the analysis was adjusted for these parameters. Fourth, the relatively short follow-up period as well as the sample size might explain the partly nonsignificant study results.

Taken together, the results of this study demonstrate that the intervention is feasible in a study setting and associated with a significant improvement of the adherence to inhaled medication in patients with chronic lung diseases. Its implementation in developed countries should be considered because nowadays nearly everyone owns a smartphone where the app and consequently the reminders could easily be installed and used. However, the use of the adherence-measurement system and the described intervention currently add additional costs to standard care. Furthermore, clinicians will need to have sufficient time to review the adherence data and to provide appropriate feedback to the patients. Considering the high initial costs and the longer consultation times compared to the nowadays-established clinical visits, one should take into account that probably initial financial outlay and invested time for the patient care, a longterm saving can be achieved as well as an offsetting of the effort by improved disease control and consequently economic benefit. This point supports the findings of a systematic review published by R. Dekhuijzen et al., which summarised the results of different clinical trials investigating clinical and economic impact of adherence in asthma and COPD patients [8]. Therefore, further work is needed to confirm the value of this intervention in routine clinical practice.

\section{Conclusions}

This study demonstrates that regular, automatic and personal reminders have a beneficial effect on taking and timing adherence of inhaled medication in asthma and COPD patients. This in turn, resulted in a trend towards a decreased frequency of exacerbation in participants assigned to the intervention group. A positive effect on time to first exacerbation as well as on QoL could not be detected. Further studies conducted in larger study populations and over extended follow-up periods are needed to verify our findings.

\section{Supplementary information}

Supplementary information accompanies this paper at https://doi.org/10. 1186/s12931-019-1219-3.

Additional file 1. Visualization graph for SmartinhalerTM and Polymedication Electronic Monitoring System.

Additional file 2. Results of adjusted Cox regression and Poisson regression.

Additional file 3. Nonparametric Test for Time and Group Effects on Adherence.

\section{Abbreviations}

BMI: Body Mass Index; Cl: Confidence Interval; COPD: Chronic Obstructive Lung Disease; FEV1: Forced Expiratory Volume in one Second; FVC: Forced Vital Capacity; GP: General Practitioner; ICS: Inhaled Corticosteroid;

LABA: Long Acting Beta2-Agonist; LAMA: Long Acting Muscarinic Antagonist; POEMS: Polymedication Electronic Monitoring System; PY: Pack Years; QoL: Quality of Life; RR: Rate Ratio; SABA: Short Acting Beta2-Agonist; SAMA: Short Acting Muscarinic Antagonist; SD: Standard Deviation; SGRQ: St. George Respiratory Questionnaire; WHO: World Health Organisation

\section{Acknowledgements}

Special thanks to the following institution and departments for their support in recruitment of the study patients: Marketing Department (Cantonal Hospital Baselland, Liestal, Switzerland), Dr. med. A. Breitenbücher (pulmonologist, Cantonal Hospital Baselland, Bruderholz, Switzerland), Dr. med. L. Joos Zellweger (pulmonologist, Claraspital, Basel, Switzerland), Dr. med. S. Vogt (pulmonologist, Hospital Rheinfelden, Rheinfelden, Switzerland), Dr. med. M. Frey (pulmonologist, Clinic Barmelweid, Barmelweid, Switzerland) and Dr. med. D. Simonett, pulmonologist in private practice, Liestal, Switzerland).

\section{Authors' contributions}

$C G, T D$ and $J D L$ are the chief investigators of the project. CG, TD, SD, IA, KH and JDL made contributions to the protocol within the scope of their specific areas of expertise. CG recruited the study participants, followed up the adherence of the participants, did the intervention, if necessary, and contributed to the data collection during the follow-up visits. ALB and SM contributed to the recruitment of the study participants with a lot of patience and to the data collection during baseline and follow-up visits. CG and $S D$ did the data cleaning. SG, AB and AL contributed to all statistical 
analyses done for the evaluation of this data. CG prepared the first draft of this manuscript, AL contributed significantly to writing and revising the manuscript in its subsequent stages and all co-authors read and agreed with the final version of the manuscript. The corresponding author had full access to the data and had final responsibility for the decision to submit for publication. The corresponding author attests that all listed authors meet authorship criteria and that no others meeting the criteria have been omitted. CG is the guarantor. All authors read and approved the final manuscript.

\section{Funding}

This project was financially supported by grants from the Gottfried und Julia Bangerter-Rhyner Foundation, Bern, Switzerland, the Swiss Academy of Medical Sciences (SAMW), Bern, Switzerland, the Freiwillige Akademische Gesellschaft (FAG), Basel, Switzerland and the Swiss Lung League, Berne, Switzerland. Further financial support was provided by unrestricted grands from Boehringer Ingelheim GmbH Switzerland, Astra Zeneca AG Switzerland and Mundipharma AG Switzerland.

The funding agencies respectively pharmaceutical companies have no bearing on the study design, data collection and analysis or writing of the manuscript.

\section{Availability of data and materials}

The used raw data during this study are available from the corresponding author on reasonable request.

\section{Ethics approval and consent to participate}

The study was conducted in accordance with the guiding principles of the Declaration of Helsinki and was approved by the local ethics Committee northwest/central Switzerland (EK- 269/13). Written informed consent was obtained from all participants before study start.

\section{Consent for publication}

Not applicable.

\section{Competing interests}

The authors declare that they have no competing interests.

\section{Author details}

${ }^{1}$ University Clinic of Medicine, Cantonal Hospital Baselland, Rheinstrasse 26, $\mathrm{CH}$ - 4410 Liestal, Switzerland. 'Department of Pharmaceutical Sciences, University of Basel, Basel, Switzerland. ${ }^{3}$ Faculty of Medicine, University of Basel, Basel, Switzerland. ${ }^{4}$ Centre for Primary Health Care, University of Basel, Basel, Switzerland. ${ }^{5}$ Department of Clinical Pharmacology and Toxicology, University Hospital Basel, Basel, Switzerland.

\section{Received: 11 February 2019 Accepted: 17 October 2019}

Published online: 03 December 2019

\section{References}

1. World Health Organization. Global surveillance, prevention and control of chronic respiratory diseases: a comprehensive approach. 2007. Available: http://www.who.int/gard/publications/GARD\%20Book\%202007.pdf?ua=1. Accessed 19 Oct 2018

2. Normansell R, Kew KM, Stovold E. Interventions to improve adherence to inhaled steroids for asthma. Cochrane Database Syst Rev. 2017;4:CD012226.

3. Sulaiman I, Cushen B, Greene G, Seheult J, Seow D, Rawat F, et al. Objective assessment of adherence to inhalers by patients with chronic obstructive pulmonary disease. Am J Respir Crit Care Med. 2017;195:1333-43.

4. Mueller S, Wilke T, Bechtel B, Punekar YS, Mitzner K, Virchow JC. Nonpersistence and non-adherence to long-acting COPD medication therapy: a retrospective cohort study based on a large German claims dataset. Respir Med. 2017;122:1-11

5. Jung E, Pickard AS, Salmon JW, Bartle B, Lee TA. Medication adherence and persistence in the last year of life in COPD patients. Respir Med. 2009;103: 525-34.

6. World Health Organization. Adherence to long-term therapies: evidence for action. 2003. Available: http://www.who.int/chp/knowledge/publications/ adherence_full_report.pdf?ua=1. Accessed 19 Oct 2018.

7. van Boven JF, Chavannes NH, van der Molen T, Rutten-van Molken MP, Postma MJ, Vegter S. Clinical and economic impact of non-adherence in COPD: a systematic review. Respir Med. 2014;108:103-13.
8. Dekhuijzen R, Lavorini F, Usmani OS, van Boven JFM. Addressing the impact and unmet needs of nonadherence in asthma and chronic obstructive pulmonary disease: where do we go from Here? J Allergy Clin Immunol Pract. 2018:6:785-93.

9. Bourbeau J, Bartlett SJ. Patient adherence in COPD. Thorax. 2008;63:831-8.

10. Engelkes $M$, Janssens HM, de Jongste JC, Sturkenboom MC, Verhamme KM. Medication adherence and the risk of severe asthma exacerbations: a systematic review. Eur Respir J. 2015;45:396-407.

11. Celli BR, MacNee W, Force AET. Standards for the diagnosis and treatment of patients with COPD: a summary of the ATS/ERS position paper. Eur Respir J. 2004:23:932-46.

12. Toy EL, Gallagher KF, Stanley EL, Swensen AR, Duh MS. The economic impact of exacerbations of chronic obstructive pulmonary disease and exacerbation definition: a review. COPD. 2010;7:214-28.

13. Durr S, Hersberger KE, Zeller A, Scheuzger J, Miedinger D, Gregoriano C, et al. The integrated care of asthma in Switzerland (INCAS)-study: Patients' perspective of received asthma care and their interest in asthma education. J Asthma. 2016;53:955-63.

14. Durr S, Hersberger KE, Zeller A, Scheuzger J, Miedinger D, Gregoriano C, et al. The Integrated Care of Asthma in Switzerland (INCAS) study: changes in asthma control and perception of health care through asthma education. Respiration. 2017;94:416-23.

15. Williams LK, Peterson EL, Wells K, Ahmedani BK, Kumar R, Burchard EG, et al. Quantifying the proportion of severe asthma exacerbations attributable to inhaled corticosteroid nonadherence. J Allergy Clin Immunol. 2011;128: 1185-91 e2.

16. Stern L, Berman J, Lumry W, Katz L, Wang L, Rosenblatt L, et al. Medication compliance and disease exacerbation in patients with asthma: a retrospective study of managed care data. Ann Allergy Asthma Immunol. 2006:97:402-8.

17. Toy EL, Beaulieu NU, McHale JM, Welland TR, Plauschinat CA, Swensen A, et al. Treatment of COPD: relationships between daily dosing frequency, adherence, resource use, and costs. Respir Med. 2011;105:435-41.

18. Demonceau J, Ruppar T, Kristanto P, Hughes DA, Fargher E, Kardas P, et al. Identification and assessment of adherence-enhancing interventions in studies assessing medication adherence through electronically compiled drug dosing histories: a systematic literature review and meta-analysis. Drugs. 2013;73:545-62.

19. Allemann SS, Nieuwlaat R, Navarro T, Haynes B, Hersberger KE, Arnet I. Congruence between patient characteristics and interventions may partly explain medication adherence intervention effectiveness: an analysis of 190 randomized controlled trials from a Cochrane systematic review. J Clin Epidemiol. 2017:91:70-9.

20. Gregoriano C, Dieterle T, Durr S, Arnet I, Hersberger KE, Leuppi JD. Impact of an electronic monitoring intervention to improve adherence to inhaled medication in patients with asthma and chronic obstructive pulmonary disease: study protocol for a randomized controlled trial. JMIR Res Protoc. 2017;6:e204

21. Gregoriano C, Dieterle T, Breitenstein AL, Durr S, Baum A, Maier S, et al. Use and inhalation technique of inhaled medication in patients with asthma and COPD: data from a randomized controlled trial. Respir Res. 2018;19:237.

22. Global Initiative for Asthma (GINA). Global strategy for asthma management and prevention. 2017. Available from: https://ginasthma org/wp-content/uploads/2019/04/wmsGINA-2017-main-report-final_V2. pdf. Accessed 8 Aug 2019.

23. The Global Strategy for the Diagnosis, Management and Prevention of COPD, Global Initiative for Chronic Obstructive Lung Disease (GOLD). 2017. Available from: https://goldcopd.org/gold-2017-global-strategy-diagnosismanagement-prevention-copd/. Accessed 8 Aug 2017.

24. Rodriguez-Roisin R. Toward a consensus definition for COPD exacerbations. Chest. 2000;117:398S-401S.

25. Eisen SA, Hanpeter JA, Kreuger LW, Gard M. Monitoring medication compliance: description of a new device. J Compliance Health Care. 1987;2:131-42.

26. Hansen RA, Kim MM, Song L, Tu W, Wu J, Murray MD. Comparison of methods to assess medication adherence and classify nonadherence. Ann Pharmacother. 2009:43:413-22.

27. Jones PW, Quirk FH, Baveystock CM. The St George's Respiratory Questionnaire. Respir Med. 1991;85(Suppl B):25-31 discussion 3-7.

28. R Core Team. R: A Language and Environment for Statistical Computing. $R$ Foundation for Statistical Computing, 2013. http://www.R-project.org/. ISBN 3-900051-07-0. [p38]. 
29. Noguchi K, Gel YR, Brunner E, Konietschke F. nparLD: An R software package for the nonparametric anlysis of longitudinal data in factorail experiments. J Stat Softw. 2012;50:1-23.

30. Vogelmeier C, Hederer B, Glaab T, Schmidt H, Rutten-van Molken MP, Beeh $\mathrm{KM}$, et al. Tiotropium versus salmeterol for the prevention of exacerbations of COPD. N Engl J Med. 2011;364:1093-103.

31. Wedzicha JA, Banerji D, Chapman KR, Vestbo J, Roche N, Ayers RT, et al. Indacaterol-Glycopyrronium versus Salmeterol-fluticasone for COPD. N Engl J Med. 2016;374:2222-34

32. Molloy GJ, O'Carroll RE, Witham MD, McMurdo ME. Interventions to enhance adherence to medications in patients with heart failure: a systematic review. Circ Heart Fail. 2012;5:126-33.

33. Marceau C, Lemiere C, Berbiche D, Perreault S, Blais L. Persistence, adherence, and effectiveness of combination therapy among adult patients with asthma. J Allergy Clin Immunol. 2006;118:574-81.

34. Cushen B, Sulaiman I, Greene G, MacHale E, Mokoka M, Reilly RB, et al. The clinical impact of different adherence behaviors in patients with severe chronic obstructive pulmonary disease. Am J Respir Crit Care Med. 2018;197:1630-3.

35. Makela MJ, Backer V, Hedegaard M, Larsson K. Adherence to inhaled therapies, health outcomes and costs in patients with asthma and COPD. Respir Med. 2013;107:1481-90.

36. Elliott RA, Boyd MJ, Salema NE, Davies J, Barber N, Mehta RL, et al. Supporting adherence for people starting a new medication for a longterm condition through community pharmacies: a pragmatic randomised controlled trial of the new medicine service. BMJ Qual Saf. 2016;25:747-58.

37. Lyons I, Barber N, Raynor DK, Wei L. The medicines advice service evaluation (MASE): a randomised controlled trial of a pharmacist-led telephone based intervention designed to improve medication adherence. BMJ Qual Saf. 2016;25:759-69.

38. Haynes RB, Ackloo E, Sahota N, McDonald HP, Yao X. Interventions for enhancing medication adherence. Cochrane Database Syst Rev. 2008;2: CD000011.

39. Sulaiman I, Greene G, MacHale E, Seheult J, Mokoka M, D'Arcy S, et al. A randomised clinical trial of feedback on inhaler adherence and technique in patients with severe uncontrolled asthma. Eur Respir J. 2018;51:1701126.

40. Checchi KD, Huybrechts KF, Avorn J, Kesselheim AS. Electronic medication packaging devices and medication adherence: a systematic review. JAMA. 2014;312:1237-47

41. Chan AH, Stewart AW, Harrison J, Camargo CA Jr, Black PN, Mitchell EA. The effect of an electronic monitoring device with audiovisual reminder function on adherence to inhaled corticosteroids and school attendance in children with asthma: a randomised controlled trial. Lancet Respir Med. 2015:3:210-9.

42. Foster JM, Usherwood T, Smith L, Sawyer SM, Xuan W, Rand CS, et al. Inhaler reminders improve adherence with controller treatment in primary care patients with asthma. J Allergy Clin Immunol. 2014;134:1260-8 e3.

43. Tommelein E, Mehuys E, Van Hees T, Adriaens E, Van Bortel L, Christiaens T, et al. Effectiveness of pharmaceutical care for patients with chronic obstructive pulmonary disease (PHARMACOP): a randomized controlled trial. Br J Clin Pharmacol. 2014;77:756-66.

44. Mes MA, Katzer CB, Chan AHY, Wileman V, Taylor SJC, Horne R. Pharmacists and medication adherence in asthma: a systematic review and metaanalysis. Eur Respir J. 2018;52:1800485.

45. Coleman Cl, Limone B, Sobieraj DM, Lee S, Roberts MS, Kaur R, et al. Dosing frequency and medication adherence in chronic disease. J Manag Care Pharm. 2012;18:527-39.

46. Boeni F, Hersberger KE, Arnet I. Multidrug punch cards in primary care: a mixed methods study on patients' preferences and impact on adherence. Front Pharmacol. 2014;5:220.

47. Chisholm-Burns MA, Spivey CA, Graff Zivin J, Lee JK, Sredzinski E, Tolley EA. Improving outcomes of renal transplant recipients with behavioral adherence contracts: a randomized controlled trial. Am J Transplant. 2013; 13:2364-73.

48. Powell LH, Calvin JE Jr, Richardson D, Janssen I, Mendes de Leon CF, Flynn $\mathrm{KJ}$, et al. Self-management counseling in patients with heart failure: the heart failure adherence and retention randomized behavioral trial. JAMA. 2010;304:1331-8.

49. Jarab AS, Alqudah SG, Khdour M, Shamssain M, Mukattash TL. Impact of pharmaceutical care on health outcomes in patients with COPD. Int J Clin Pharm. 2012;34:53-62.
50. Khdour MR, Kidney JC, Smyth BM, McElnay JC. Clinical pharmacy-led disease and medicine management programme for patients with COPD. Br J Clin Pharmacol. 2009;68:588-98.

51. Bourbeau J, Sebaldt RJ, Day A, Bouchard J, Kaplan A, Hernandez P, et al. Practice patterns in the management of chronic obstructive pulmonary disease in primary practice: the CAGE study. Can Respir J. 2008;15:13-9.

52. Wickstrom G, Bendix T. The "Hawthorne effect"--what did the original Hawthorne studies actually show? Scand J Work Environ Health. 2000;26:363-7.

\section{Publisher's Note}

Springer Nature remains neutral with regard to jurisdictional claims in published maps and institutional affiliations.
Ready to submit your research? Choose BMC and benefit from:

- fast, convenient online submission

- thorough peer review by experienced researchers in your field

- rapid publication on acceptance

- support for research data, including large and complex data types

- gold Open Access which fosters wider collaboration and increased citations

- maximum visibility for your research: over $100 \mathrm{M}$ website views per year

At BMC, research is always in progress.

Learn more biomedcentral.com/submissions 